\title{
Correction to: Understanding Determinants of Patient Preferences Between Stool Tests and Colonoscopy for the Assessment of Disease Activity in Inflammatory Bowel Disease
}

\author{
Maria Barsky ${ }^{1} \cdot$ Joseph Meserve ${ }^{1} \cdot$ Helen Le ${ }^{1} \cdot$ Angelina Collins $^{1} \cdot$ Siddharth Singh ${ }^{1} \cdot$ Brigid Boland $^{1}$. \\ William J. Sandborn ${ }^{1} \cdot$ Parambir S. Dulai ${ }^{1}$
}

Published online: 8 February 2021

(c) Springer Science+Business Media, LLC, part of Springer Nature 2021

\section{Correction to: Digestive Diseases and Sciences https://doi.org/10.1007/s10620-020-06568-w}

The original version of the article unfortunately contained an error in the acknowledgment content. The corrected acknowledgment with the UCSD Gastroenterology T32 training grant (DK 0070202) is given below.

Acknowledgment Parambir S. Dulai is supported by an American Gastroenterology Association Research Scholar Award. Brigid Boland is supported by a grant from the NIH/NIDDK (K23DK123406). Siddharth Singh is supported by NIH/NIDDK (K23DK117058), ACG Junior Faculty Development Award and the Crohn's and Colitis Foundation Career Development Award (\#404614). William Sandborn is partially supported by NIDDK-funded San Diego Digestive Diseases Research Center (P30 DK120515). This study was supported by the UCSD Gastroenterology T32 training grant (DK 0070202).

Publisher's Note Springer Nature remains neutral with regard to jurisdictional claims in published maps and institutional affiliations.

The original article can be found online at https://doi.org/10.1007/ s10620-020-06568-w.

Parambir S. Dulai

pdulai@health.ucsd.edu

1 Division of Gastroenterology, University of California San Diego, La Jolla, CA 92093, USA 